\title{
Corrigendum
}

\section{The rationale behind autologous autoimmune hematopoietic stem cell transplant conditioning regimens: concerns over the use of total body irradiation}

R Burt, K Kallunian, D Patel and J Thomas

Bone Marrow Transplantation (2005) 35, 105. doi:10.1038/sj.bmt.1704796

Correction to: Bone Marrow Transplantation (2004) 34, 745-751. doi:10.1038/sj.bmt.1704671
In an editorial published in $B M T$ in the November 1, 2004 issue entitled 'The rationale behind autologous autoimmune hematopoietic stem cell transplant conditioning regimens: concerns over the use of total body irradiation', Kenneth Kallunian (sic) was included as an author in error. His name should be deleted as a coauthor. 